\title{
Uncoupling ribosome biogenesis regulation from RNA polymerase I activity during herpes simplex virus type 1 infection
}

\author{
STÉPHANE BELIN, ${ }^{1,2}$ KARINE KINDBEITER, ${ }^{3}$ SABINE HACOT, ${ }^{1,2}$ MARIE ALEXANDRA ALBARET, ${ }^{1,2,3}$ \\ JEAN-XAVIER ROCA-MARTINEZ, ${ }^{1,2,3}$ GABRIEL THÉRIZOLS, ${ }^{1,2}$ OLIVIER GROSSO, ${ }^{4}$ \\ and JEAN-JACQUES DIAZ ${ }^{1,2}$ \\ ${ }^{1}$ Centre National de la Recherche Scientifique (CNRS), Université de Lyon, Lyon F-69003, France \\ ${ }^{2}$ Centre de Génétique Moléculaire et Cellulaire, Centre Léon Bérard, Université de Lyon, Lyon F-69373, France \\ ${ }^{3}$ Idéalp-Pharma, Villeurbanne, Cedex 69603, France \\ ${ }^{4}$ L'Institut de Physique Nucléaire de Lyon (INPL), Université de Lyon, Villeurbanne, Cedex 69622, France
}

\begin{abstract}
The ribosome is the central effector of protein synthesis, and its synthesis is intimately coordinated with that of proteins. At present, the most documented way to modulate ribosome biogenesis involves control of rDNA transcription by RNA polymerase I (RNA Pol I). Here we show that after infection of human cells with herpes simplex virus type 1 (HSV-1) the rate of ribosome biogenesis is modulated independently of RNA Pol I activity by a dramatic change in the rRNA maturation pathway. This process permits control of the ribosome biogenesis rate, giving the possibility of escaping ribosomal stress and eventually allowing assembly of specialized kinds of ribosomes.
\end{abstract}

Keywords: HSV-1; pre-rRNA; ribosome; RNA polymerase I

\section{INTRODUCTION}

Ribosome biogenesis is a complex process that takes place mainly within the nucleoli of eukaryotes. This process requires more than 200 factors (Coute et al. 2006) for a coordinated synthesis, maturation, assembly, and export into the cytoplasm of functional ribonucleic particles containing some 80 proteins and four ribosomal RNA (rRNA) (Lafontaine and Tollervey 2001). Recent studies tend to demonstrate that eukaryotic rRNA, like their prokaryotic counterparts, are ribozymes, allowing peptide bond formation as well as proofreading activities of the ribosomes (Cech 2000). Three of the four rRNA (18S, 5.8S, and 28S) result from sequentially ordered and highly specific cleavages of an unique 45S rRNA-precursor synthesized by RNA polymerase 1 (RNA Pol I). Simultaneously, pre-rRNA are subjected to extensive chemical

Reprint requests to: Jean-Jacques Diaz, Centre de Génétique Moléculaire et Cellulaire, Centre Léon Bérard, Université de Lyon, Lyon F-69373, France; e-mail: diazjj@lyon.fnclcc.fr; fax: 33-4-72432685.

Article published online ahead of print Article and publication date are at http://www.rnajournal.org/cgi/doi/10.1261/rna.1935610. modifications such as methylations and pseudouridylations (Fromont-Racine et al. 2003) at defined sites, and particularly on nucleotides involves in catalysis. The exact function of these modifications is not yet elucidated, but it appears more and more clear that they play a major role in controlling the translational activity of the ribosomes (Yoon et al. 2006; Baxter-Roshek et al. 2007; Chaudhuri et al. 2007).

Productive infection with herpes simplex virus type 1 (HSV-1) consists of a highly ordered expression program of about 80 genes (immediate-early, early, and late genes) that leads to formation of viral progeny and cell death (Roizman and Sears 1990). Viral gene expression is accompanied by important modifications of cellular gene expression regulation that occurs at both the transcription (Harris-Hamilton and Bachenheimer 1985) and the posttranscriptional levels (Greco et al. 2000). We have previously shown that after infection of HeLa cells with HSV-1, the rate of synthesis of stable cytoplasmic ribosomes is sustained until the early phase of infection and then is progressively decreased by an unknown mechanism (Simonin et al. 1997). According to the current idea generally accepted, one might have expected that the observed HSV-1 
induced decrease of ribosome production would be preceded by a decrease of nuclear rRNA precursor (45S prerRNA), reflecting an inhibition of RNA Pol I activity. In this study, we demonstrate that ribosome biogenesis might be controlled not only at the level of RNA polymerase I activity, but also at post-transcriptional cleavage steps of the large pre-rRNA precursor.

\section{RESULTS AND DISCUSSION}

\section{RNA Pol I activity is maintained during HSV-I infection}

To verify the activity of RNA Pol I, HeLa cells were infected with HSV-1 in experimental conditions, allowing a complete viral cycle in about $12 \mathrm{~h}$ (Fig. 1A), and the level of pre-rRNA 45S accumulation was evaluated by Northern blot analyses of nuclear RNA purified at different times post-infection (p.i.) (Fig. 1B). As shown in Figure 1A, ICP27, UL42, and US11 viral proteins are detected at the correct times p.i., confirming the complete progress of the viral cycle. As shown in Figure 1B, the steady-state level of $45 \mathrm{~S}$ was unchanged in infected cells compared with that of mock-infected (m.i.) cells, even at $12 \mathrm{~h}$ p.i. This was observed with the three different probes complementary to the sequence of $18 \mathrm{~S}, 5.8 \mathrm{~S}$, and $28 \mathrm{~S}$ of the pre-rRNA $45 \mathrm{~S}$.

To confirm this result, the intranuclear localization of pre-rRNA 45S-together with its level of accumulationwas then determined by fluorescent in situ hybridization (FISH) during the course of infection (Fig. 1C). In m.i. cells, the fluorescent signal accumulated mainly in nucleoli (unambiguously identified by colocalization experiments with nucleolar proteins B23 and nucleolin; data not shown). After infection, the signal followed the expected important virally induced nucleolar morphology modifications (Besse and Puvion-Dutilleul 1996), although its global intensity did not decrease even at $12 \mathrm{~h}$ p.i. Altogether, these results indicate that the steady-state level of $45 S$ pre-RNA was unaffected after infection. It is generally accepted that the level of $45 \mathrm{~S}$ pre-RNA decreases rapidly after blockage of RNA Pol I or after abrogation of ribosome formation (Ebert et al. 2008). This $45 \mathrm{~S}$ pre-rRNA shortage was observed in our experimental system after a second cycle of viral replication (by Northern blot and FISH) and when blocking RNA Pol I activity by actinomycin D treatment (data not shown). Thus, as $45 \mathrm{~S}$ pre-rRNA levels are maintained upon infection, our data suggest that RNA Pol I was still active.

To further confirm this finding, radioactive pulse-labeling was performed with ${ }^{3} \mathrm{H}$-uridine, and production of mature cytoplasmic rRNA ( $18 \mathrm{~S}$ and $28 \mathrm{~S}$ ) and nuclear $45 \mathrm{~S}$ pre-rRNA was measured. For this, nuclear and cytoplasmic RNA were purified. Cytoplasmic radioactive $18 \mathrm{~S}$ and $28 \mathrm{~S}$ rRNA were extracted from agarose gels after separation by electropho- resis, and radioactivity incorporated in these species was measured directly by scintillation counting (Fig. 1D). Nuclear rRNA were separated by electrophoresis through agarose gel, transferred to a nitrocellulose membrane. Radioactivity in the $45 \mathrm{~S}$ pre-rRNA specie was then evaluated using a PhosporImager (Fig. 1E). As expected (Simonin et al. 1997), infection induced a progressive impairment of incorporation of radioactive $18 \mathrm{~S}$ and $28 \mathrm{~S}$ into cytoplasmic ribosomes (Fig. 1D). In these conditions, the rate of ribosome biogenesis at $3 \mathrm{~h}$ p.i. was already only about $30 \%$ of that of m.i. cells for both $18 \mathrm{~S}$ and $28 \mathrm{~S}$ rRNA. This decreased rate reached a plateau representing about $10 \%-$ $15 \%$ of that of m.i. cells. Conversely, synthesis of the $45 \mathrm{~S}$ precursor persisted all along infection at a rate only slightly inferior to that of m.i. cells (Fig. 1E). For example, at $3 \mathrm{~h}$ p.i., the rate of $45 \mathrm{~S}$ synthesis was about $90 \%$ of that of m.i. cells and was never below $80 \%$, even at late times p.i. Altogether these results clearly demonstrate that RNA Pol I activity is only slightly impaired following infection while an important decrease of ribosome biogenesis occurs.

We next explored whether the decrease of cytoplasmic ribosomes production could be due to a degradation of ribosomes occurring within cytoplasm. Northern blot analysis of cytoplasmic RNA showed that the level of $18 \mathrm{~S}$ and $28 \mathrm{~S}$ remained stable during the course of infection (Fig. 1F), with no increase of degradation products visible below the mature $18 \mathrm{~S}$ and $28 \mathrm{~S}$ (even after overexposure of the membranes). These results clearly indicated that cytoplasmic ribosomes are not degraded during infection and suggested that the decrease of ribosome synthesis was due to a post-transcriptional mechanism occurring within nuclei of infected cells.

\section{Pre-rRNA maturation pathways are altered during HSV-1 infection}

We consequently wondered whether and at which steps during ribosome biogenesis the maturation of rRNA was affected. Northern blot analyses of HeLa nuclear RNA using a set of three different probes allowed us to identify all the previously described pre-rRNA intermediates that represent the signatures of what are designated pathways $\mathrm{A}$ and $\mathrm{B}$ (Hadjiolova et al. 1993) and the more recently described $26 \mathrm{~S}$ intermediate (Rouquette et al. 2005) (Fig. 2A,B-D, m.i. lanes). The same analysis performed with nuclear RNA purified at different times p.i. revealed a profound and progressive alteration of pre-rRNA pattern (Fig. 2B). Fine quantification of the relative amounts of each RNA species for each condition using dedicated software (see Materials and Methods) allowed us to characterize three types of modifications: (1) a decrease in the amount of 41S, 32S, 21S, and 12S; (2) a stability in the amount of $45 \mathrm{~S}$ and $30 \mathrm{~S}$; and (3) the appearance of new rRNA-containing rRNA species, which we have named V1, V2, and V3 (for viralinduced forms 1,2 , and 3 , respectively). 
A

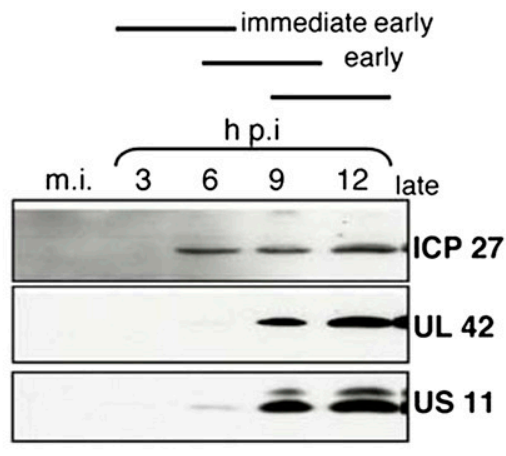

B

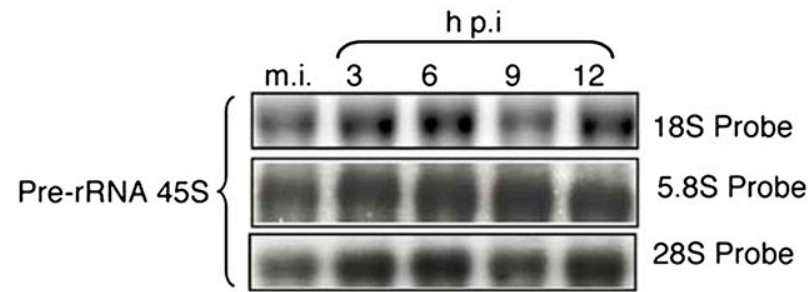

C

DAPI
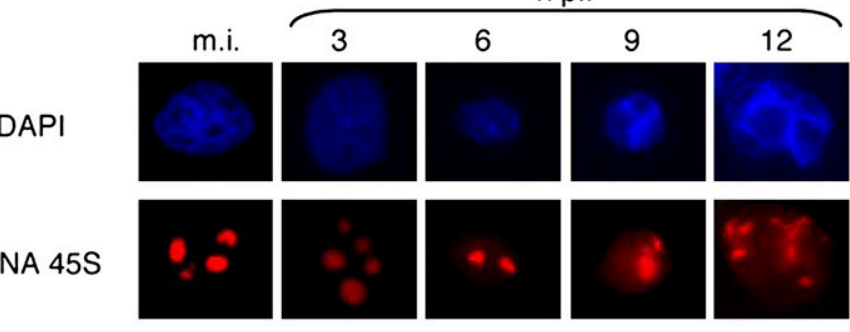

hp.i

D

a.u.

rRNA 18S

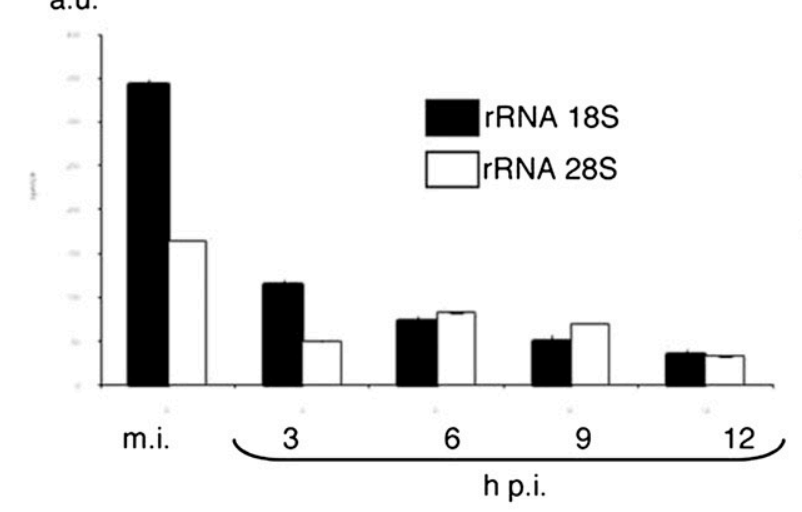

E

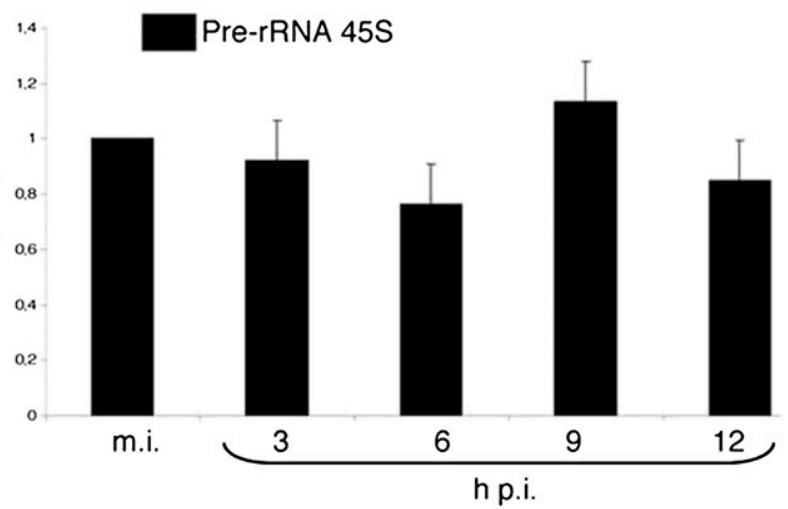

F
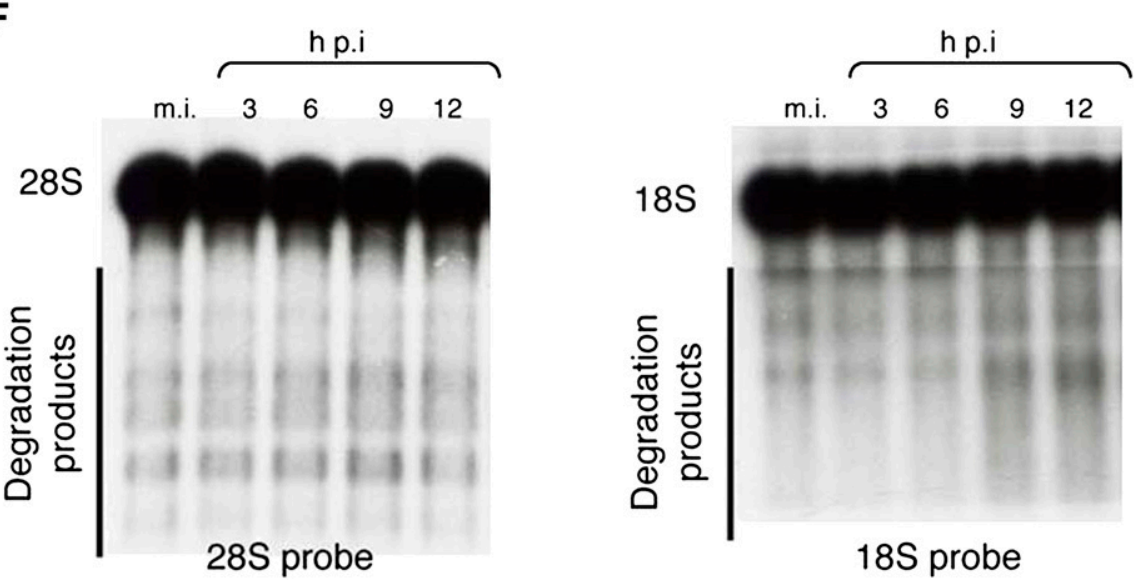

FIGURE 1. Preservation of RNA Pol I activity and inhibition of ribosome biogenesis after HSV-1 infection. (A) Correct and complete progress of the viral cycle was checked by Western blot allowing the detection of three viral proteins specifically synthesized at each phase of the viral cycle. ICP27, UL42, and US11 are markers of the three phases. (B) Northern blot analysis using three different probes complementary to the sequence of $18 \mathrm{~S}, 5.8 \mathrm{~S}$, and $28 \mathrm{~S}$ shows that the steady-state level of $45 \mathrm{~S}$ pre-rRNA is equivalent in m.i. and infected cells at any time p.i. (C) FISH analysis using a probe specific for $45 \mathrm{~S}$ pre-rRNA detection shows the expected virally induced redistribution of this pre-rRNA without decrease of its amount. $(D)$ Quantification of the amount of $\left[{ }^{3} \mathrm{H}\right]$ uridine incorporated into cytoplasmic $18 \mathrm{~S}$ and $28 \mathrm{~S}$ mature rRNAs, expressed in arbitrary units (a.u.), shows a decrease of cytoplasmic ribosome biogenesis after infection. Bar indicates mean and s.e.m. $(n=6)$. (E) Quantification of the amount of $\left[{ }^{3} \mathrm{H}\right]$ uridine incorporated into $45 \mathrm{~S}$ pre-rRNA shows a relative stability of production of the pre-rRNA during the course of infection. The amount of radioactivity is expressed in percentages with the value obtained for m.i. cells taken as a reference. Bar indicates mean and s.e.m. $(n=3)$. $(F)$ Northern blot analysis of cytoplasmic RNA performed with probes $28 \mathrm{~S}$ and $18 \mathrm{~S}$ shows that the levels of rRNA $18 \mathrm{~S}$ and $28 \mathrm{~S}$ remain constant during the course of infection and that there is no increase of rRNA degradation products (visible below $28 \mathrm{~S}$ and 18S) during infection. 

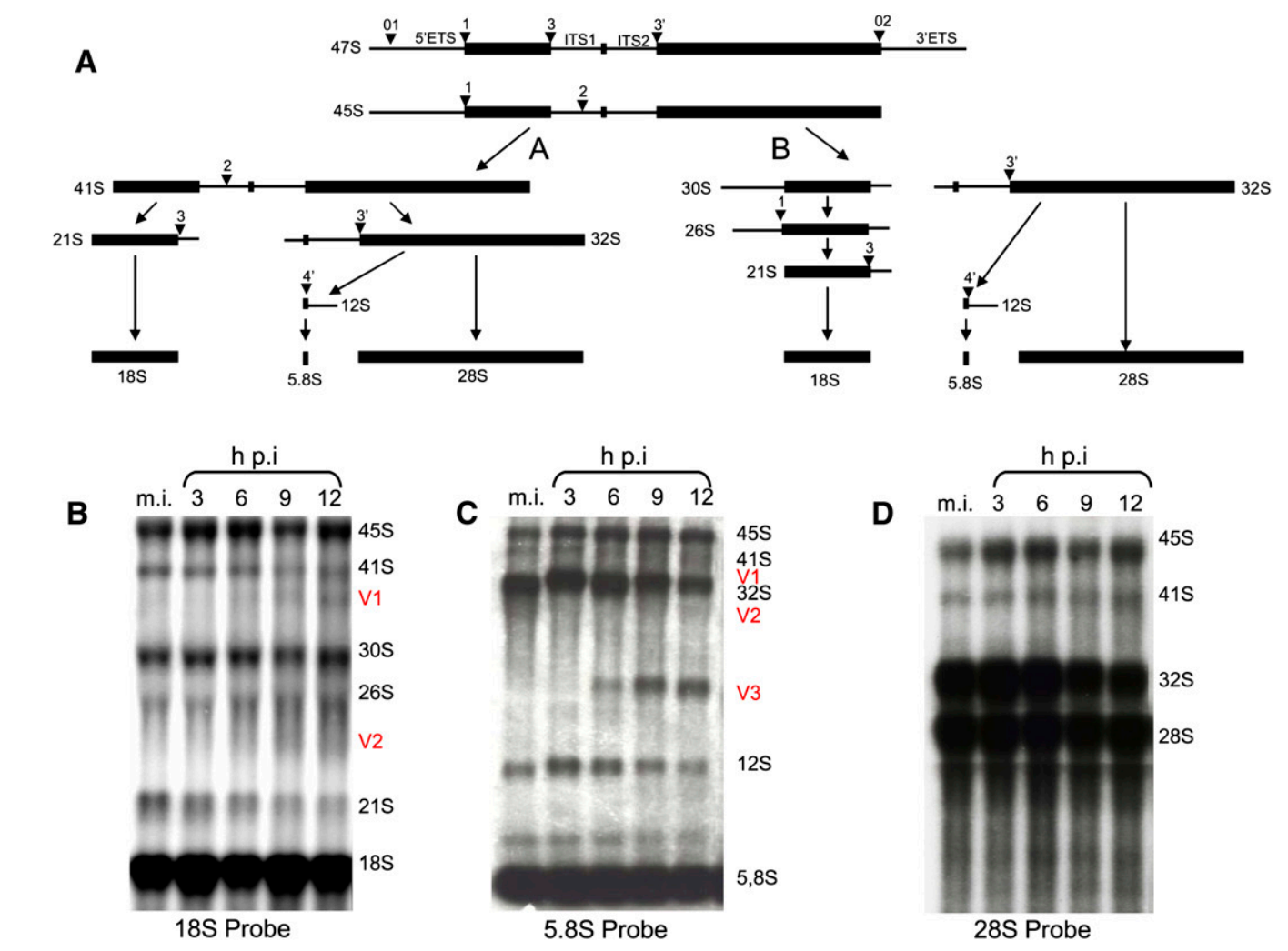

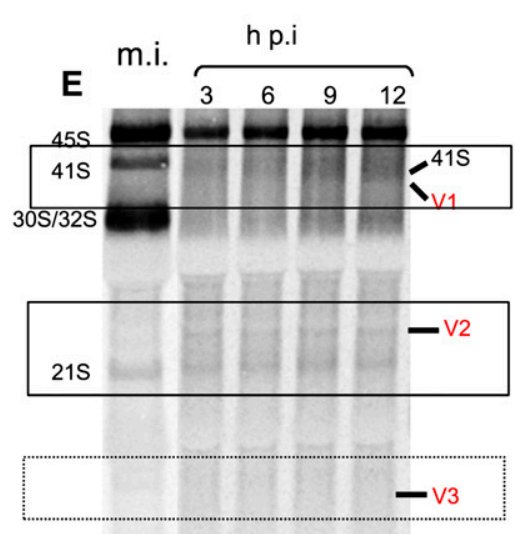

$12 S$
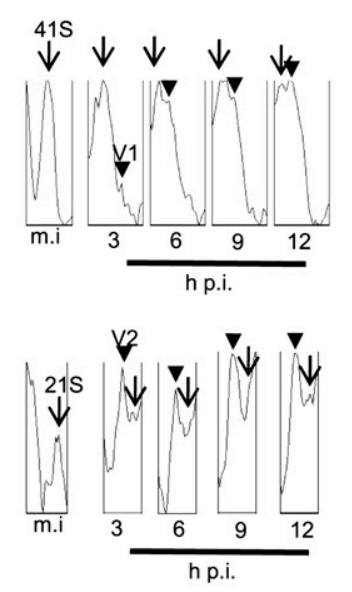

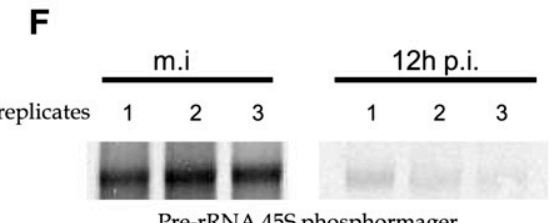

Pre-rRNA 45S phosphormager

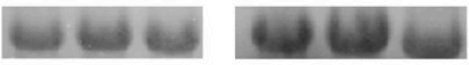

rRNA 28S Ethidium Bromide

FIGURE 2. Alteration of rRNA processing after HSV-1 infection. (A) Simplified diagram of the two major pre-RNA processing pathways in HeLa cells. Thin lines represent the sequences that are eliminated during the processing (5'ETS, ITS1, ITS2, $3^{\prime}$ ETS) to provide mature rRNA (18S, $5.8 \mathrm{~S}$, and $28 \mathrm{~S}$ ), which are represented by black boxes. Names of the intermediates are given according to the current nomenclature. Positions of the main cleavage sites are indicated by arrowheads with conventional numbering (Hadjiolova et al. 1993). (B-D) Northern blot analyses of nuclear RNAs performed with probes $18 \mathrm{~S}(B), 5.8 \mathrm{~S}(C)$, and $28 \mathrm{~S}(D)$ show that HSV-1 infection induces a modification of the nuclear pre-rRNA intermediates profile present in m.i. cells and an appearance of new intermediates V1, V2, and V3 (indicated in red). Compared with a m.i. profile, the amounts of $45 \mathrm{~S}$ pre-rRNAs and $30 \mathrm{~S}$ remain equivalent during infection while the amounts of 41S, 21S, and 12S pre-rRNAs decrease and that of $26 \mathrm{~S}$ pre-rRNA increases. These changes are visible as soon as $3 \mathrm{~h}$ p.i. and are progressively exacerbated. V1, V2, and V3 are visible at $6 \mathrm{~h}$ p.i. and continue to accumulate at late times p.i. (E) Image of pulse chase analysis after PhosphoImager scanning (left); software analysis of the band (right). Arrows indicate either 41S or 21S; arrowheads indicate either V1 or V2. The results shows that the virally induced rRNA species are produced early in infection $\left(3 \mathrm{~h}\right.$ p.i.). $(F)\left[{ }^{3} \mathrm{H}\right]$ methyl methionine labeling shows that during infection by HSV-1, the global level of methylation of rRNA is strongly decreased. The $28 \mathrm{~S}$ rRNA observed by ethidium bromide is used as loading control. 
We next monitored the kinetic of appearance of these three new rRNA species. For this, we performed pulse labeling experiments of $1 \mathrm{~h}$ with $\left[{ }^{3} \mathrm{H}\right]$ uridine at different times p.i. and separated the resulting total RNA through agarose gels, which were then submitted for PhosphorImager and ImageJ analysis (Fig. 2E). First, this analysis confirmed very clearly the maintained synthesis of $45 \mathrm{~S}$ during the course of infection and the early decrease of the majority of pre-rRNA visible as soon as $3 \mathrm{~h}$ p.i., underlying the rapid decrease of cytoplasmic ribosome production (Fig. 1). Second, this analysis showed that V1, V2, and V3 are produced early in infection since they are already detected at $3 \mathrm{~h}$ p.i. In Figure $2 \mathrm{E}, \mathrm{V} 2$ is easily distinguisible at $3 \mathrm{~h}$ p.i., and its level of production seems to remain stable all along infection. In Figure 2E, it is more difficult to distinguish V1 because its position is close to that of the 41S intermediate. However, a close inspection of the gel, and Image J analysis (Fig. 2E, right panel) unambiguously showed that V1 is also produced at $3 \mathrm{~h}$ p.i. and its production is higher at late times p.i. $(9 \mathrm{~h})$ than at early times p.i. $(3 \mathrm{~h})$. In Figure $2 \mathrm{E}, \mathrm{V} 2$ is easily distinguishable whereas V3 is detected only very slightly.

In parallel, analysis of the global level of rRNA methylation, using metabolic labeling with $\left[{ }^{3} \mathrm{H}\right]$ methyl-methionine (Fig. 2F) showed a reproducible strong inhibition of this process (of more than $80 \%$ ) at late times during infection (12 h p.i.). This result shows that HSV-1 infection induces a strong impairment of rRNA methylation. This could account for the perversion of some post-transcriptional steps of ribosome biogenesis observed in infected cells, particularly cleavages of pre-rRNA, as has been demonstrated in yeast when rRNA methylation is altered (Tollervey et al. 1993), and ultimately for the virally induced decrease of ribosome production. We do not know by which mechanism this decrease of rRNA methylation could occur; however, interestingly, we have demonstrated recently that HSV-1 infection induces a profound reorganization of nucleolar architecture with an important redistribution of fibrillarin out of the nucleolar compartment at $6 \mathrm{~h}$ p.i. (Callé et al. 2008).

\section{New precursors of pre-rRNA are specifically expressed during HSV-1 infection}

Extensive Northern blot analyses were then performed with nuclear RNA purified from infected cells, using a set of seven probes to elucidate the structure of these species. Probes complementary to the two external and the two internal transcribed sequences (ITS1 and 2 and $5^{\prime}$ and $3^{\prime}$ ETS) were used in addition to the three probes used in Figure 2. A summary of this analysis is presented in Figure $3 \mathrm{~A}$. V1 was detected with probes specific for $5^{\prime}$-ETS, 18S, ITS1, 5.8S, and ITS2 but not with those recognizing $28 \mathrm{~S}$ and $3^{\prime}$-ETS. V2 was detected with probes specific for $18 \mathrm{~S}$, ITS1, 5.8S, and ITS2 but not with the other probes. V3 was intensely detected with probes specific for $5.8 \mathrm{~S}$ and ITS2 and less intensely with probe specific for ITS1. V3 was not detected with the other probes. All the other rRNA intermediates were detected with the expected corresponding probes. These analyses together with the relative position of these three RNA on the Northern blot compared with that of the other well characterized pre-rRNA allowed us to define their structure (Fig. 3B). V1 contains the entire sequences coding for $18 \mathrm{~S}$ and $5.8 \mathrm{~S}$ rRNA and the complete ITS1 together with sequences from $5^{\prime}$ ETS and ITS2. V2 contains sequences coding for $18 \mathrm{~S}$ and the entire $5.8 \mathrm{~S}$ rRNA, the complete ITS1, and sequences from ITS2. V3 contains the entire 5.8S and sequences from ITS1 and ITS2.

To identify the nucleotide sequences of the $5^{\prime}$ and $3^{\prime}$ extremities of the three virally induced rRNA species (V1, $\mathrm{V} 2$, and V3), we have adapted the technique of circularization RT-PCR (cRT-PCR) (Couttet et al. 1997). This method allowed us to determine precisely the two extremities of V1, V2, and V3. The results of the sequencing are presented in Figure 3C. The three rRNA precursors exhibited the same $3^{\prime}$ extremity localized in position 7721 of the $45 \mathrm{~S}$ sequence. V1 started at position 570 in the $5^{\prime}$ ETS, V2 started at position 3637 in the end of the 5' ETS, and V3 started at position 5600 in the ITS1.

Pulse labeling experiments showed that these three RNA species are continuously produced all during infection. V1 and V2, which are already accumulated at $6 \mathrm{~h}$ p.i., contained the $18 \mathrm{~S}$ together with the $5.8 \mathrm{~S}$ sequence and, therefore, resulted from early cleavages localized between the end of ITS2 and the beginning of 28S. Surprisingly, the structure of these three pre-rRNA is particularly unusual and could be considered as a feature of a nonproductive virally induced pathway. Indeed, according to classical descriptions of the eukaryotic ribosome biogenesis pathways, crucial cleavages between $18 \mathrm{~S}$ and $5.8 \mathrm{~S}$ sequences lead very rapidly to a physical separation of the early $90 \mathrm{~S}$ particle into pre- $40 \mathrm{~S}$ and pre-60S subunits, which thereafter undergo independent maturation pathways (Lafontaine and Tollervey 2001). In addition, the fact that V1-V3 species were never found within cytoplasmic ribosomes-even after careful inspection of their contents-strongly suggests that they were degraded in the nuclear compartment. The observation that this pool of pre-rRNA $45 \mathrm{~S}$ is subjected to degradation is confirmed by the metabolic labeling experiments. The radioactivity incorporated into the terminal forms of pre-rRNAs species (i.e., nuclears $18 \mathrm{~S}$ and $28 \mathrm{~S}$ ) also decreased during the course of infection (Fig. 2B-D) similarly to that incorporated into cytoplasmic $18 \mathrm{~S}$ and $28 \mathrm{~S}$ (data not shown), while there was a maintenance of the production of $45 \mathrm{~S}$. In addition, the lack of nuclear accumulation of mature rRNAs suggests that they were still exported to the cytoplasm (data not shown), reinforcing the already demonstrated notion that nuclear export signal (NES)-dependent export (Sandri-Goldin 1998) required for ribosome export (Moy and Silver 1999) was still functional after infection. 
A

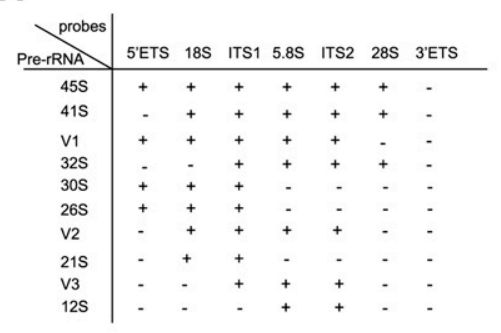

B

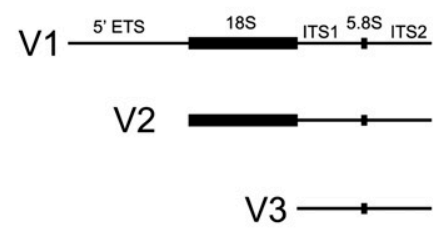

C

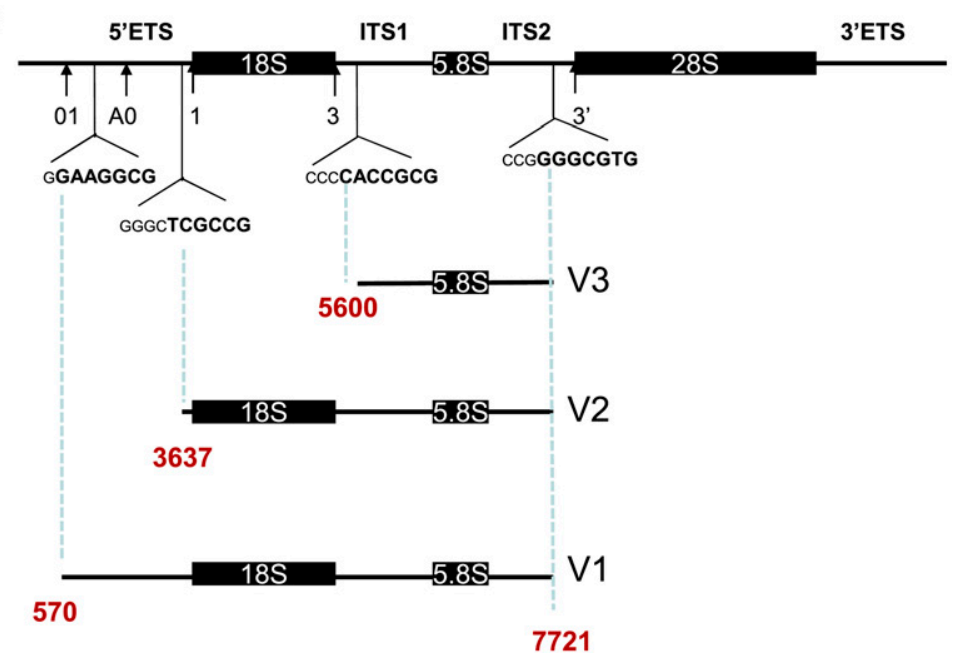

FIGURE 3. Structure of the virally induced V1, V2, and V3 pre-rRNA species. (A) Extensive Northern blot analysis with seven probes. Names of probes and of pre-rRNAs are given. In the table, the + sign indicates that the RNA species present on the Northern blot was detected by the corresponding probe whereas the - sign indicates that the RNA species was not detected. (B) Integration of the results presented in $A$ allows us to design the sequence of the three virally induced pre-rRNAs. V1 displays sequences contained in the 5'ETS, 18S, ITS1, 5.8S, and ITS2; V2 displays sequences contained into the 18S, ITS1, and ITS2; V3 displays sequences contained in the $5.8 \mathrm{~S}$ and in ITS1 and ITS2. $(C)$ cRT-PCR experiment was performed to determine the $5^{\prime}$ and $3^{\prime}$ extremities of the three virally induced rRNA species. Sequencing of the PCR products allowed us to determine the cleavage site on the pre-rRNA sequence. Positions and sequences of V1, V2, and V3 are indicated according to the nomenclature deposited in National Center for Biotechnology Information Nucleotide NM U13369.

\section{Hypothetical model of HSV-1 induced ribosome biogenesis modifications}

As summarized in Figure 4, one might conclude from our data that during the course of infection, one fraction of the pool of $45 \mathrm{~S}$ pre-rRNA produced continues to be correctly processed following pre-existing pathways A and B. However, quantification of the pre-rRNA intermediates, specific for both pathways (Fig. 2), showed that pathway B is used with the same efficiency in noninfected and infected cells (illustrated by the same relative amount of pre-rRNA $30 \mathrm{~S}$ in both conditions) and that pathway $\mathrm{A}$ is used less efficiently in infected cells (illustrated by a decrease of the relative pre-rRNA 41S amount). The other fraction of the pool of $45 \mathrm{~S}$ pre-rRNA produced is submitted to an as-yetundescribed post-transcriptional processing, leading to the nuclear accumulation of the three virally induced pre-rRNA intermediates that we have called V1, V2, and V3.

There are two distinct but not exclusive explanations for the existence of this post-transcriptional regulation of ribosome biogenesis that has been conserved during evolution. First, the observation that ribosome biogenesis is impaired after infection by HSV-1 without inhibiting RNA Pol I activity could provide a unique molecular mechanism for the virus to escape what is now recognized as ribosomal stress (Lohrum et al. 2003; Zhang et al. 2003; Dai and Lu 2004; Dai et al. 2004). Ribosomal stress induces cell cycle arrest and apoptosis through a p53-mediated mechanism. In nonstressed cells, MDM2 (an E3 ubiquitin ligase) binds to p53 and promotes degradation via the proteasome. When RNA Pol I activity is altered, following various kind of stresses such as Actinomycin D treatment (Ashcroft et al. 2000), amino acid starvation, or even cell-cell contact inhibition (Bhat et al. 2004), there is an increase of the free pool of ribosomal proteins (RP) L5, L11, and L23 in the nucleoplasm disturbing the MDM2-p53 complex by direct interaction between these RP and MDM2, leading to a stabilization of p53 that can exert its proapoptotic functions (Horn and Vousden 2008). Therefore, maintaining the RNA Pol I activity and the subsequent global production of pre-rRNA intermediates probably allows the capture of the same level of RP in noninfected and infected cells and therefore precludes the activation of the ribosomal stress. Indeed, we have shown that HSV-1 infection induces a decrease of p53 level (data not shown). This observation is in favor of this first proposed possibility since the capture of RP by V1-V3 should leave a free pool of MDM2 and the subsequent degradation of $\mathrm{p} 53$.

Second, the observation that ribosome biogenesis is impaired after infection by HSV-1 without inhibiting RNA Pol I activity could provide a unique molecular mechanism to engineer ribosomes containing specific features. In our laboratory, we have performed extensive analyses of the ribosomes after HSV-1 infection. From these analyses it can be concluded that after infection: (1) The protein composition of the newly synthesized ribosomes could differ from that of the pre-existing ribosomes. In fact, after infection, a number of ribosomal proteins are 


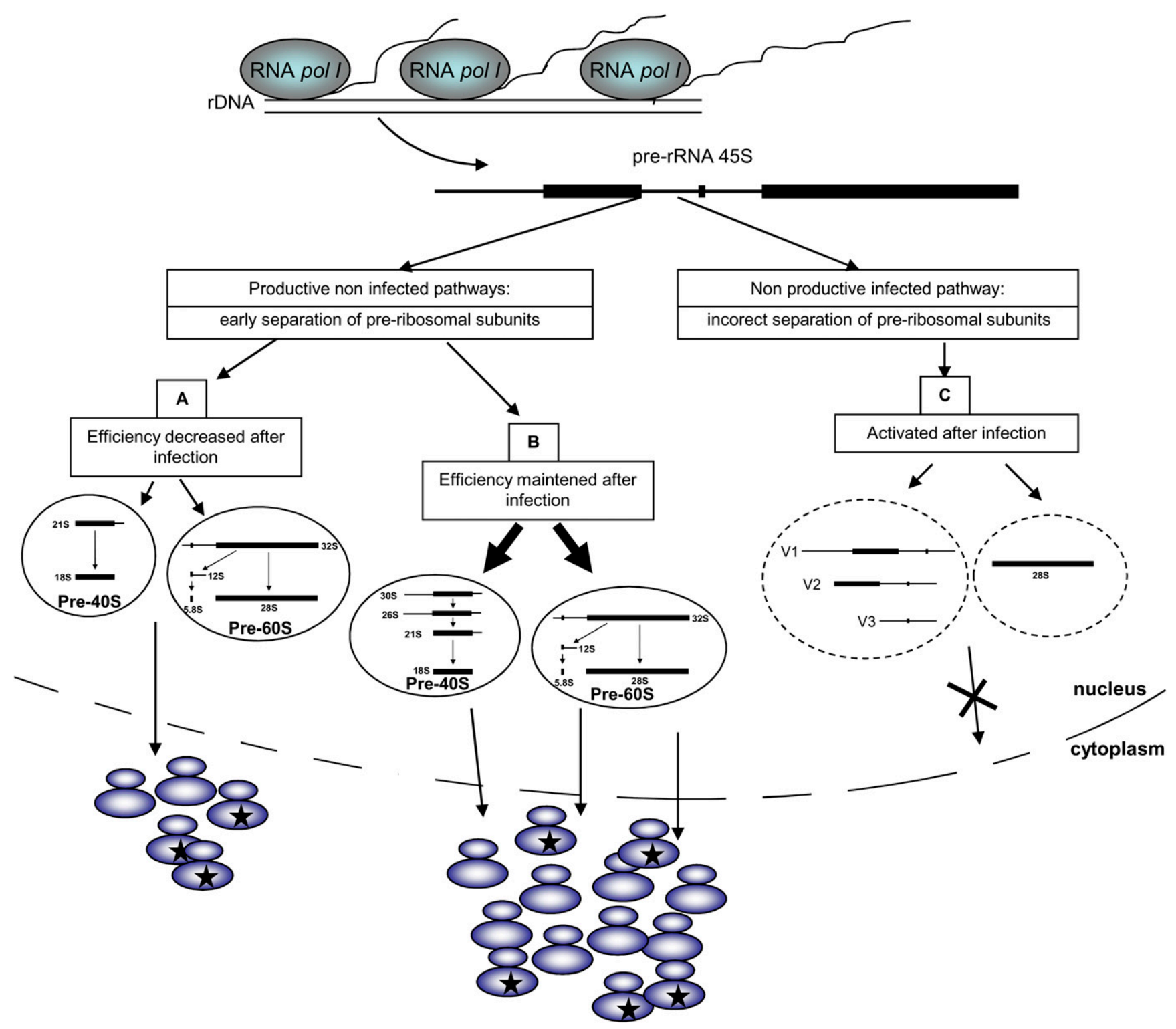

FIGURE 4. Virally induced modification of rRNA processing: hypothetical consequences for ribosome function. Previous data and data presented in this study allow design of a model in which the RNA pol I activity is preserved after infection although there is a decrease in the biogenesis of cytoplasmic ribosomes. In this model, the continuous production of a $45 \mathrm{~S}$ pre-rRNA allows biogenesis, by pre-existing pathways $\mathrm{A}$ and $\mathrm{B}$, of highly modified ribosomes whereas induction of a new nonproductive pathway of pre-rRNA maturation permits stoppage of ribosome biogenesis without inducing the deleterious ribosomal stress.

over-represented in the ribosome cytoplasmic pool (RPL4, RPL11, RPL22, RPL30, RPL35, RPL39, and RPS27) whereas others are under-represented in this pool (RPS6, RPL6, RPL7, RPL7a) (Simonin et al. 1997). (2) Several RPs undergo important and highly specific post-translational modifications. Some of them are specifically phosphorylated: RPS2a, RPS2, RPS3a, RPS6, and especially a unique case of phosphorylation for RPL30 (Fenwick and Walker 1979; Kennedy et al. 1981; Garcin et al. 1990; Masse et al. 1990a,b; Simonin et al. 1995a). (3) Nonribosomal cellular (PABP1) (Greco et al. 2001) and viral (US11, VP16, VP19C) proteins are specifically associated to ribosomes
(Simonin et al. 1995b; Diaz et al. 1996). Therefore, taken together, these pieces of evidence allow us to postulate that the complex post-transcriptional regulation of ribosome biogenesis that we have unraveled in this study and that takes place after infection could permit the synthesis and assembly of several kinds of ribosomal machineries (indicated by ribosomes marked by a star in Fig. 4). By definition, these modifications can only take place at the post-transcriptional stages, and obviously, a virally induced alteration of only the amount of pre-rRNAs $45 \mathrm{~S}$ production through the modulation of RNA Pol I activity would not have permitted them to occur. However, whether these 
different kinds of ribosomes specifically synthesized after infection are functional remains to be determined.

\section{Concluding remarks}

In this work, analysis of infected human cells has allowed us to discover an asyet-unraveled alternative process for ribosome production control under pathological conditions. This demonstrates that the modes of regulation of this major fundamental cell process are indeed more complex than was thought previously and include crucial posttranscriptional regulatory steps. Interestingly, this mode of regulation is reminiscent of mRNA expression regulation, and one can speculate that it allows the monitoring of the production of a sufficient amount of functional ribosomes, participating directly in gene expression regulation and pathological processes. However, at present, whether this alternative mode of ribosome control production takes place in other physiological and/or pathological conditions remains to be determined.

\section{MATERIALS AND METHODS}

\section{Cells, infection, and metabolic radioactive labeling}

HeLa cells (ATCC CCL-2) were cultured in Eagle's essential minimum medium (EMEM, Sigma) supplemented with $5 \%$ fetal bovine serum and $2 \mathrm{mM}$ glutamine at $37^{\circ} \mathrm{C}$ with $5 \% \mathrm{CO}_{2}$. Infections with HSV-1 (MP strain) were performed as described previously (Simonin et al. 1997). For metabolic labeling, cells were incubated for $1 \mathrm{~h}$ in MEM supplemented with 5\% dialyzed fetal calf serum (FCS) containing either $\left[{ }^{3} \mathrm{H}\right]$ uridine at $15 \mu \mathrm{Ci} / \mathrm{mL}(\mathrm{GE}$ Healthcare) or $\left[{ }^{3} \mathrm{H}\right]$ methyl-methionine at $15 \mu \mathrm{Ci} / \mathrm{mL}$. At the end of labeling period, cells were washed three times with ice-cold phosphate-buffered saline (PBS) containing $10^{-4} \mathrm{M}$ uridine.

\section{rRNA analysis}

Nonradioactive and radioactive RNA were purified (RNeasy KIT, Qiagen) from cytoplasmic and nuclear fractions obtained after cell lysis performed at $4^{\circ} \mathrm{C}$ with $0.5 \%(\mathrm{v} / \mathrm{v})$ Nonidet P-40 in $50 \mathrm{mM}$ Tris- $\mathrm{HCl}$ ( $\mathrm{pH} \mathrm{8}$ ) containing $140 \mathrm{mM} \mathrm{NaCl}$ and $1.5 \mathrm{mM} \mathrm{MgCl}$. Northern blots were performed as described previously (Coute et al. 2007). For labeling, 50 pmoles of each probe were incubated with 50 pmoles of $\left[\gamma-{ }^{32} \mathrm{P}\right] \mathrm{ATP}$ and $\mathrm{T} 4$ polynucleotide kinase (Promega) during $30 \mathrm{~min}$ at $37^{\circ} \mathrm{C}$. Sequences of the probes are listed in Table 1 . For each experimental condition, the radioactivity contained in every band corresponding to known rRNA species was quantified using PhosphorImager (Typhoon, GE Healthcare) scanning and ImageQuant TL software (GE Healthcare). $18 \mathrm{~S}$ and $28 \mathrm{~S}$ rRNA visualized by ethidium bromide was used as loading control.
Radioactive nuclear RNAs were separated in formaldehyde agarose gels, transferred to nitrocellulose membranes. Radioactivity was measured after exposure of the membranes using a PhosphoImager system (Typhoon and ImageJ software, GE Healthcare). Radioactive cytoplasmic RNAs were separated in agarose gels, $18 \mathrm{~S}$ and $28 \mathrm{~S}$ RNAs were purified, and the amount of incorporated radioactivity was measured after solubilization in a scintillation fluid using a liquid scintillator counter.

\section{Fluorescence in situ hybridization}

The experiments were performed as described (Morency et al. 2007). HeLa cells were seeded at $1.5 \times 10^{5}$ cells per well in 24 -well plates that contained coverslips. The next day, the cells were infected by HSV-1 virus. At different times of infection, the cells were rinsed in $1 \times$ PBS and fixed with $4 \%$ formaldehyde in $1 \times$ PBS for $10 \mathrm{~min}$. The cells were rinsed again in $1 \times \mathrm{PBS}$ and incubated overnight at $4^{\circ} \mathrm{C}$ in $70 \%$ ethanol. The cells were then rehydrated for $5 \mathrm{~min}$ in $2 \times$ SSC with $50 \%$ formamide and hybridized for $6 \mathrm{~h}$ at $37^{\circ} \mathrm{C}$ with $3 \mathrm{ng}$ of $45 \mathrm{~S}$ probe. The specificity of RNA detection was checked by RNase treatment (data not shown). Sequences of the probes are listed in Table 1.

\section{Western blot analysis}

The antibodies directed against viral proteins were used as previously described using identical protocols (Simonin et al. 1997). Proteins were resolved by SDS-PAGE and then transferred onto a polyvinylidene difluoride membrane (Immobilon-P, Millipore). The membranes were incubated with a $500 \times$ dilution of either a rabbit polyclonal anti UL42, anti-ICP27, or anti-US11 antibodies (Callé et al. 2008). Anti-ICP27 and anti-UL42 antibodies were kindly provided by H. Marsden (University of Glasgow) (antibodies 42 and Z1F11, respectively). Proteins were revealed by chemiluminescence (ECL from Amersham Biosciences) using an anti-rabbit or an anti-mouse peroxidase-conjugated antibody (Sigma) diluted $1: 10,000$.

\section{CRT-PCR}

The protocol was adapted from Couttet et al. (1997). Circularization was performed as follow: $5 \mu \mathrm{g}$ of total RNA were incubated 
with $15 \mathrm{U}$ of T4 RNA ligase (Invitrogen) in the appropriate buffer and $1 \mathrm{mM}$ of ATP for $20 \mathrm{~min}$ at $37^{\circ} \mathrm{C}$. After purification by the Trizol method, reverse transcription was performed on $400 \mathrm{ng}$ of RNA with $1 \mu \mathrm{M}$ RP primer, $1 \mathrm{mM} \mathrm{dNTP}$, and $5 \mathrm{U}$ of reverse transcriptase (Invitrogen) for $112 \mathrm{~min}$ at $42^{\circ} \mathrm{C}$. PCR amplification was performed on $200 \mathrm{ng}$ of cDNA using $1 \mu \mathrm{M}$ of each RP and FP primers (Table 1, cf. sequences) with platinum qPCR supermix (I) for 35 cycles $\left(1 \mathrm{~min}\right.$ at $94^{\circ} \mathrm{C}, 1 \mathrm{~min}$ at $60^{\circ} \mathrm{C}$, and $1 \mathrm{~min}$ at $72^{\circ} \mathrm{C}$ ). PCR products were cloned using TOPO TA cloning system (Invitrogen) and sequenced to obtain the $5^{\prime}$ and $3^{\prime}$ extremities.

\section{ACKNOWLEDGMENTS}

We thank Pierre-Emmanuel Gleizes and Valérie Choesmel for helpful advice on Northern blot analyses, Eric Morency for advice about FISH experiments, and Yasmine Tafer for her technical assistance. We are grateful to Dr. Alice Lebreton (Centre de Génétique Moléculaire, Gif-sur-Yvette, France) for critical reading of the manuscript and her advice. This work was supported by Région Rhône-Alpes grants: thématiques prioritaires and Cluster 10 and a grant of Institut National Contre le Cancer: RIBOCAN. S.B. is a recipient of a fellowship from La Ligue National Contre le Cancer and Association pour la Recherche Contre le Cancer. M.A.A. is a recipient of a fellowship from ANRT and IdéalpPharma. S.H. is a member of Université Lyon 1. J.J.D. is a member of INSERM.

Received September 23, 2009; accepted October 8, 2009.

\section{REFERENCES}

Ashcroft M, Taya Y, Vousden KH. 2000. Stress signals utilize multiple pathways to stabilize p53. Mol Cell Biol 20: 3224-3233.

Baxter-Roshek JL, Petrov AN, Dinman JD. 2007. Optimization of ribosome structure and function by rRNA base modification. PLoS One 2: e174. doi: 10.1371/journal.pone.0000174.

Besse S, Puvion-Dutilleul F. 1996. Distribution of ribosomal genes in nucleoli of herpes simplex virus type 1 infected cells. Eur J Cell Biol 71: 33-44.

Bhat KP, Itahana K, Jin A, Zhang Y. 2004. Essential role of ribosomal protein L11 in mediating growth inhibition-induced p53 activation. EMBO J 23: 2402-2412.

Callé A, Ugrinova I, Epstein AL, Bouvet P, Diaz JJ, Greco A. 2008. Nucleolin is required for an efficient herpes simplex virus type 1 infection. J Virol 82: 4762-4773.

Cech TR. 2000. Structural biology. The ribosome is a ribozyme. Science 289: 878-879.

Chaudhuri S, Vyas K, Kapasi P, Komar AA, Dinman JD, Barik S, Mazumder B. 2007. Human ribosomal protein L13a is dispensable for canonical ribosome function but indispensable for efficient rRNA methylation. RNA 13: 2224-2237.

Coute Y, Burgess JA, Diaz JJ, Chichester C, Lisacek F, Greco A, Sanchez JC. 2006. Deciphering the human nucleolar proteome. Mass Spectrom Rev 25: 215-234.

Coute Y, Kindbeiter K, Belin S, Dieckmann R, Duret L, Bezin L, Sanchez JC, Diaz JJ. 2007. ISG20L2, a novel vertebrate nucleolar exoribonuclease involved in ribosome biogenesis. Mol Cell Proteomics 7: 549-559.

Couttet P, Fromont-Racine M, Steel D, Pictet R, Grange T. 1997. Messenger RNA deadenylylation precedes decapping in mammalian cells. Proc Natl Acad Sci 94: 5628-5633.

Dai MS, Lu H. 2004. Inhibition of MDM2-mediated p53 ubiquitination and degradation by ribosomal protein L5. J Biol Chem 279: 44475-44482.
Dai MS, Zeng SX, Jin Y, Sun XX, David L, Lu H. 2004. Ribosomal protein $\mathrm{L} 23$ activates p53 by inhibiting MDM2 function in response to ribosomal perturbation but not to translation inhibition. Mol Cell Biol 24: 7654-7668.

Diaz JJ, Dodon MD, Schaerer-Uthurralt N, Simonin D, Kindbeiter K, Gazzolo L, Madjar JJ. 1996. Post-transcriptional transactivation of human retroviral envelope glycoprotein expression by herpes simplex virus Us11 protein. Nature 379: 273-277.

Ebert BL, Pretz J, Bosco J, Chang CY, Tamayo P, Galili N, Raza A, Root DE, Attar E, Ellis SR, et al. 2008. Identification of RPS14 as a $5 \mathrm{q}^{-}$syndrome gene by RNA interference screen. Nature 451: 335-339.

Fenwick ML, Walker MJ. 1979. Phosphorylation of a ribosomal protein and of virus-specific proteins in cells infected with herpes simplex virus. J Gen Virol 45: 397-405.

Fromont-Racine M, Senger B, Saveanu C, Fasiolo F. 2003. Ribosome assembly in eukaryotes. Gene 313: 17-42.

Garcin D, Masse T, Madjar JJ, Jacquemont B. 1990. Herpes simplex virus type-1 immediate-early gene expression and shut off of host protein synthesis are inhibited in neomycin-treated human epidermoid carcinoma 2 cells. Eur J Biochem 194: 279-286.

Greco A, Bausch N, Coute Y, Diaz JJ. 2000. Characterization by twodimensional gel electrophoresis of host proteins whose synthesis is sustained or stimulated during the course of herpes simplex virus type 1 infection. Electrophoresis 21: 2522-2530.

Greco A, Bienvenut W, Sanchez JC, Kindbeiter K, Hochstrasser D, Madjar JJ, Diaz JJ. 2001. Identification of ribosome-associated viral and cellular basic proteins during the course of infection with herpes simplex virus type 1. Proteomics 1: $545-549$.

Hadjiolova KV, Nicoloso M, Mazan S, Hadjiolov AA, Bachellerie JP. 1993. Alternative pre-rRNA processing pathways in human cells and their alteration by cycloheximide inhibition of protein synthesis. Eur J Biochem 212: 211-215.

Harris-Hamilton E, Bachenheimer SL. 1985. Accumulation of herpes simplex virus type 1 RNAs of different kinetic classes in the cytoplasm of infected cells. J Virol 53: 144-151.

Horn HF, Vousden KH. 2008. Cooperation between the ribosomal proteins L5 and L11 in the p53 pathway. Oncogene 27: 5774-5784.

Kennedy IM, Stevely WS, Leader DP. 1981. Phosphorylation of ribosomal proteins in hamster fibroblasts infected with pseudorabies virus or herpes simplex virus. J Virol 39: 359-366.

Lafontaine DL, Tollervey D. 2001. The function and synthesis of ribosomes. Nat Rev Mol Cell Biol 2: 514-520.

Lohrum MA, Ludwig RL, Kubbutat MH, Hanlon M, Vousden KH. 2003. Regulation of HDM2 activity by the ribosomal protein L11. Cancer Cell 3: 577-587.

Masse T, Garcin D, Jacquemont B, Madjar JJ. 1990a. Herpes simplex virus type-1-induced stimulation of ribosomal protein S6 phosphorylation is inhibited in neomycin-treated human epidermoid carcinoma 2 cells and in ras-transformed cells. Eur J Biochem 194: 287-291.

Masse T, Garcin D, Jacquemont B, Madjar JJ. 1990b. Ribosome and protein synthesis modifications after infection of human epidermoid carcinoma cells with herpes simplex virus type 1 . Mol Gen Genet 220: 377-388.

Morency E, Sabra M, Catez F, Texier P, Lomonte P. 2007. A novel cell response triggered by interphase centromere structural instability. J Cell Biol 177: 757-768.

Moy TI, Silver PA. 1999. Nuclear export of the small ribosomal subunit requires the ran-GTPase cycle and certain nucleoporins. Genes \& Dev 13: 2118-2133.

Roizman B, Sears A. 1990. Herpes simplex viruses and their replication. In Fundamental Virology (ed. BM Fields et al.), pp. 1795-1842. Raven Press, New York.

Rouquette J, Choesmel V, Gleizes PE. 2005. Nuclear export and cytoplasmic processing of precursors to the $40 \mathrm{~S}$ ribosomal subunits in mammalian cells. EMBO J 24: 2862-2872.

Sandri-Goldin RM. 1998. ICP27 mediates HSV RNA export by shuttling through a leucine-rich nuclear export signal and binding 


\section{Belin et al.}

viral intronless RNAs through an RGG motif. Genes \& Dev 12: 868-879.

Simonin D, Diaz JJ, Kindbeiter K, Denoroy L, Madjar JJ. 1995a. Phosphorylation of ribosomal protein L30 after herpes simplex virus type 1 infection. Electrophoresis 16: 854-859.

Simonin D, Diaz JJ, Kindbeiter K, Pernas P, Madjar JJ. 1995b. Phosphorylation of herpes simplex virus type 1 Us 11 protein is independent of viral genome expression. Electrophoresis 16: 1317-1322.

Simonin D, Diaz JJ, Masse T, Madjar JJ. 1997. Persistence of ribosomal protein synthesis after infection of HeLa cells by herpes simplex virus type 1. J Gen Virol 78: 435-443.
Tollervey D, Lehtonen H, Jansen R, Kern H, Hurt EC. 1993. Temperature-sensitive mutations demonstrate roles for yeast fibrillarin in pre-rRNA processing, pre-rRNA methylation, and ribosome assembly. Cell 72: 443-457.

Yoon A, Peng G, Brandenburger Y, Zollo O, Xu W, Rego E, Ruggero D. 2006. Impaired control of IRES-mediated translation in X-linked dyskeratosis congenita. Science 312: 902-906.

Zhang Y, Wolf GW, Bhat K, Jin A, Allio T, Burkhart WA, Xiong Y. 2003. Ribosomal protein L11 negatively regulates oncoprotein MDM2 and mediates a p53-dependent ribosomal-stress checkpoint pathway. Mol Cell Biol 23: 8902-8912. 

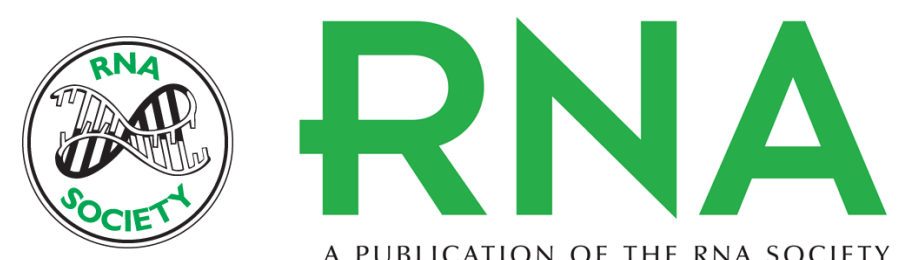

A PUBLICATION OF THE RNA SOCIETY

\section{Uncoupling ribosome biogenesis regulation from RNA polymerase I activity during herpes simplex virus type 1 infection}

Stéphane Belin, Karine Kindbeiter, Sabine Hacot, et al.

RNA 2010 16: 131-140 originally published online November 24, 2009

Access the most recent version at doi:10.1261/rna.1935610

\section{References This article cites 37 articles, 16 of which can be accessed free at: http://rnajournal.cshlp.org/content/16/1/131.full.html\#ref-list-1}

License Email Alerting $\begin{aligned} & \text { Receive free email alerts when new articles cite this article - sign up in the box at the } \\ & \text { Service }\end{aligned}$ top right corner of the article or click here. 